\title{
Wear characteristics of die surface in deep drawing of stainless steel 304 by using finite element simulation
}

\author{
Numchoak Sabangban ${ }^{1, *}$, Warit Sirikun ${ }^{1}$, Krittatee Sangounsak ${ }^{1}$ and Sedthawatt Sucharitpwatskul ${ }^{2}$ \\ ${ }^{1}$ Department of Industrial Engineering, Faculty of Engineering, Nakhon Phanom University 48000 \\ ${ }^{2}$ National Metal and Materials Technology Center (MTEC), Thailand Science Park, Pathum Thani 12120
}

\begin{abstract}
The characteristics of adhesive wear of TiN coating in drawing process by using finite element method were carried out to investigate the effects of drawing angles and sliding velocities of punch to explained wear index. Bending radius of die was used to increase the contact pressure between stainless sheet and TiN coating surface. Three sliding velocities $(0.5,1$ and $5 \mathrm{~mm} / \mathrm{s})$ were studied each bending angle between $\left(0^{\circ}\right.$ to $\left.90^{\circ}\right)$ by keeping the hardness of material coating to $24 \mathrm{GPa}$ (HV.0.05). The results showed that the wear index were decreased with drawing angle but sliding speed of punch was not affected in slightly speed.
\end{abstract}

\section{INTRODUCTION}

The demand for stainless steel has significantly increased for automotive industries due to their effective performance in mass production of safety parts and specific assembly in engine parts. [1] In the automotive sector the several of stainless steel was essential application in components parts such as fuel system, head gasket, windscreen wipers and safety part. These were tested to demonstrate and improved their suitability of car making from mechanical properties, corrosion resistance, and forming ability to other material parts. On the one hand, that their strength increases as they are cold formed into the shape of the component by conventional or advanced forming methods. In stamping process, the galling is the major issue to reduced tool life and terribly appearance of final product parts. The contact pressures (being bending) of sheet and die was increased and undesirable to prevent galling. As a result, adhesive wear of the interaction between die-sheet in the drawing process of stainless steel must be understood and develop to increase tool life quality of parts.

[2] was verify the FEM deep-drawing model with experiments variety conditions such as sliding times and hardness of TiNi. The comparison results of punch forces were shown characteristic of pseudoelasticity is greater with increased beneficial wear resistance of TiNi alloy. The major failure from FEM model was shown wrinkling point deepened on die temperature, sheet thickness and die temperature.

[3] introduction concept of a device for deep drawing in extreme conditions, represents drawing process in vacuum by high temperatures and molybdenum sheets forming. The functional of structural, economical, technological, operational, safety, environmental, legal and design requirements was investigated with description of possible variants of the mechanism structure. The initial blank metal sheet was deformed to complicated geometry shape by punch force in deep drawing process. Wrinkling and deep drawing parameters under different Blank-Holder Pressure were studied the behaviour by 3- Dimensional elasto-plastic Finite Element (FE) model for Mild Steel IS 2062 [4]. Deep drawing is the geometry process parameters that effected on deformation characteristic. [5] used 3-D experiment blank-holder pressure to identified coefficient of friction (COF) and improved quality of aluminium alloys.

According to interaction surfaces between blank and die in deep drawing process, [6] frictional condition, surface asperities on the micro deep drawing differ from that in normal scale. A Finite Element (FE) model representing surface morphology of SUS304 sheets was built for micro deep drawing simulation. [7] The local stress in SUS304 was measured during tensile deformation. Tensile stress was stopped at engineering strains of $0.33 \%, 0.78 \%$ and $0.43 \%$, respectively.

However, stamping process are permanently used multi tools that affected unpredictable wear phenomena due to interaction surface friction between sheet metal (which will be deformed) and the tool. [8] identifying wear mechanism in the main surface on Tin coated steel sheet. In additional two conditions of advanced PVD coatings were studied and experimented to improve wear characteristics resistant on punch and die surface with the friction coefficient of this sheet against some selected coatings under stamping process. Results confirm show that the Titanium Nitride (TiN) covered steel sheet to die and punch ensuring a longer life of these parts. Due to [9] shown the structural of Diamond like carbon (DLC) coatings have high wear resistance and low coefficient of friction. On the other hand the wear rate of Titanium Nitride and Titanium Carbon Nitride (TICN) TiN/TICN were increase at the high load values. 
[10] The sliding friction characteristics and wear mechanism of the TiAlN/TiN was calculated in the sliding test and observed by Environmental scanning electron microscope (ESEM) and an Energy Dispersive X-Ray Fluorescence Spectrometer (EDX) by investigated the combine action of the peeling off, chipping off, adhesion and mechanical scratch of the Titanium Aluminium Nitride (TiAlN); TiAlN/TiN coated tool.

\section{Finite Element Simulation Method}

A schematic geometry of the one-sided deep drawing test was shown in Fig. 1(a). The sheet having an initial state on the drawing die in Fig. 1(b). During the deep drawing process the punch was moving down vertically direction and pulling the sheet pass drawing die to Ushape bending, which surface of stainless sheet was contact with drawing die.

The deep drawing simulation set-up is displayed in Fig. 1. The FE 2D nonlinear plane strain, static structural has been analysed by Marc software. The geometry of punch has been selected to rigid body, the die and sheet are set to be deformable bodies in Table 1. In addition the material properties of sheet and die coating are stainless steel 304 (SS304) and TiN were based on [11] and [12] respectively. The assumption of Coulomb arctangent (velocity) is applied to all of contact body area with coefficient of friction in dry contact surface is 0.3 and moreover the boundary conditions of FE setup was shown in Fig 2. The boundaries of right surface nodes has been fixed displacement in horizontal $\mathrm{x}$ direction in order to present the haft of symmetry in geometric body. The relative sliding velocities between sheet and die were started from punch velocities under investigation by 0.5 , 1 and $5 \mathrm{~mm} / \mathrm{s}$ respectively in vertical $-\mathrm{y}$ axis and the die angles start from 0 to 90 degree are shown in Table 2 . The displacement of punch travel is $20 \mathrm{~mm}$ from the beginning point. The number of elements of sheet and die are show in Table 1. All element types analysed by using Plain Strain full integral by keeping Explicit Large Strain.

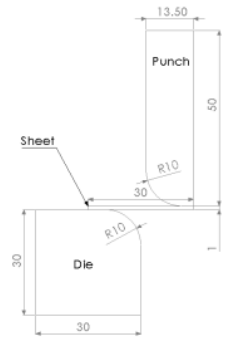

(a)

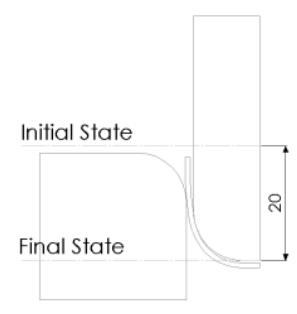

(b)
Fig. 1. (a) Geometries of the one-sided deep drawing and (b) geometries and final state of deep drawing.

$$
\frac{\partial x}{\partial t}=0
$$

Fig 2. Boundary Condition
Table 1 Type of contact body and number of elements

\begin{tabular}{|c|c|}
\hline Contact body & Contact Type (Number of Elements) \\
\hline Die & Deformable (845) \\
\hline Sheet & Deformable (749) \\
\hline Punch & Rigid (-) \\
\hline
\end{tabular}

Table 2 Parameter Condition

\begin{tabular}{|l|l|r|}
\hline Contact Body & Type of parameters & Conditions \\
\hline Die & Radius $(\mathrm{mm})$ & 10 \\
\cline { 2 - 3 } & Angle (Degree) & $0-90$ \\
\hline Punch & Velocity $(\mathrm{mm} / \mathrm{s})$ & $0.5,1$ and 5 \\
\hline Sheet & Thickness $(\mathrm{mm})$ & 1 \\
\hline
\end{tabular}

\subsection{Material Properties}

The Finite Element Analysis (FEA) studied parameters are shown in Table 3. obtained from [12] experimental TiN wear tests and Fig. 3. [13] shows true stress of SUS 304 tensile tests. Those results leading to the relative sliding velocity and normal stress values can be exacted from the FE simulations results.

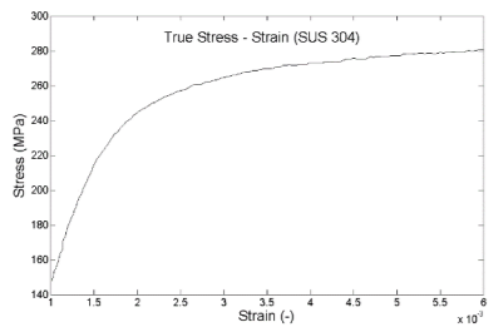

Fig 3. True stress of SUS 304 tensile tests

\subsection{Wear Model}

The following equation wear rate of die surface can be established by Archard's wear model [14] in Eq. (1)

$$
\dot{w}=\frac{K}{H} \sigma_{n} V_{\text {rel }}
$$

Where $\dot{\mathrm{w}}$ is the wear rate per times of drawing is, $\mathrm{K}$ is wear coefficient, $\mathrm{H}$ is the indentation hardness in order to shown the Vicker Hardness (Hv) of materials, $\sigma_{\mathrm{n}}$ is normal stress at identified contact area and $V_{\text {rel }}$ is the relative velocities of contact body.

During the interaction contact, sheet was moving down to surface radius of the die. Difference surface angles provide difference value of normal stress and relative sliding speed values was shown in Fig 4.

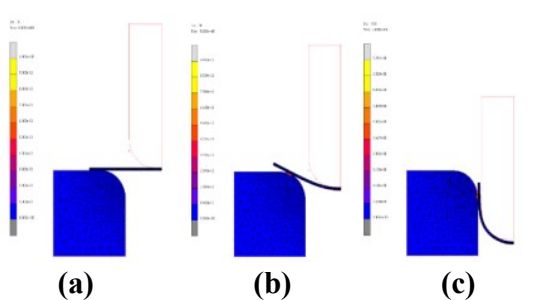

Fig. 4. (a) Initaial state (increment 0), (b) increment 50 and (c)

Final state increment 100 
Table 3 Values of experimental TiN and SUS304

\begin{tabular}{|c|c|c|c|c|}
\hline Properties & Symbols & Unit & TiN & SUS304 \\
\hline $\begin{array}{c}\text { Young's } \\
\text { modulus }\end{array}$ & $E$ & $\mathrm{GPa}$ & 341.9 & 196.12 \\
\hline $\begin{array}{c}\text { coefficient of } \\
\text { Poisson }\end{array}$ & $v$ & - & 0.19 & 0.275 \\
\hline Hardness & $H$ & $\begin{array}{c}\mathrm{GPa} \\
(\mathrm{HV})\end{array}$ & 25.6 & 2.1 \\
\hline $\begin{array}{c}\text { Wear } \\
\text { Coefficient }\end{array}$ & $K$ & $\mu N^{-1}$ & 0.15 & - \\
\hline Yield Stress & $\sigma_{y}$ & $\mathrm{MPa}$ & - & 271.2 \\
\hline $\begin{array}{c}\text { Friction } \\
\text { coefficient }\end{array}$ & $\mu$ & - & 0.3 & 0.3 \\
\hline
\end{tabular}

To a great extent Eq. (1) in FEM, the relative of velocities directions and normal stress can be estimated by Cauchy's stress formula [15] in Eq. (2).

And

$$
t(N)=-t(-N)=-t(n)
$$

$$
\sigma_{n}=t(n) \cdot n
$$

Where $\mathrm{t}(\mathrm{N})$ is the traction on a body at its surface element with the normal direction $\mathrm{N}$, and $\mathrm{n}$ is the normal vector inward.

For determining the synopsis of relative velocity vector of die and sheet it can be obtain by Eq. (4).

$$
V_{r e l}=V_{n s}-V_{n d}
$$

The $V_{n s}$ is velocity of node inside element of sheet body and $\mathrm{V}_{\text {nd }}$ velocity of node inside element of die body. In this studied the die element was set to zero, thrust the velocity of die element was neglected. Leading to only parameter of $\mathrm{V}_{\mathrm{ns}}$ can be explained by Eq. (5).

$$
V_{\text {rel }}=V_{n s} \cos (\beta)
$$

Where $\cos \beta$ is the drawing angle of $V_{n}$ is shown in Fig. 5(a)

In the FE simulations, the wear rate from Eq. (1) can be calculated to predict die surface wear, Wear Index (WI) after each increment steps. Leading to Eq. (6) can be calculated by

$$
W I=\sum_{i=1}^{N} \dot{W}
$$

Where $\mathrm{N}$ is the total number of increment and $\mathrm{i}$ is the initial increment.

The arc curve of die surface was investigated by determined number of nodes in the arc length of die surface is shown in Fig. 5(b). is 20 nodes (between node number 911 to 930 ).

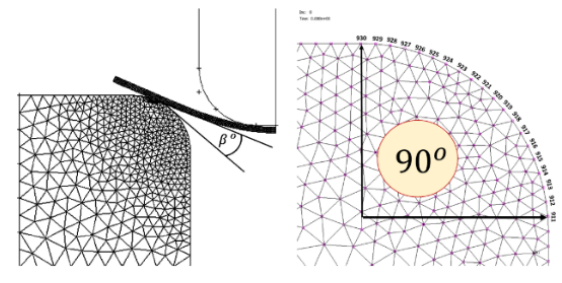

Fig 5. (a) Drawing angle and (b) nodes in the arc length of die surface

\subsection{Scientifically prof and Verification}

This FE model was analyzed under thin thickness (XY plane) was less than sheet geometry depth (Z direction), the total deformation could be assumed to plane strain. On the other hand velocities of punch are $0.1,1$ and $5 \mathrm{~mm} / \mathrm{s}$, respectively. Fig. 6 was shown the plane die force verification with mesh resolution results.

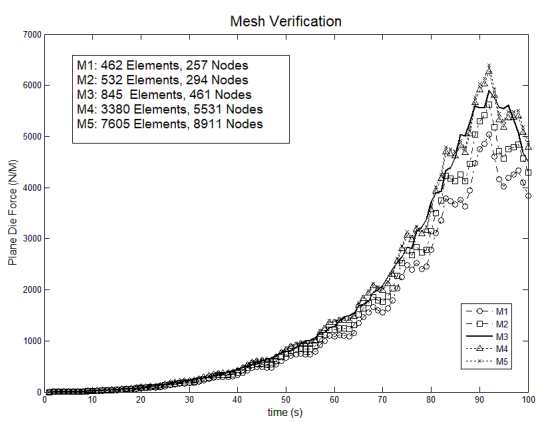

Fig 6. Plane die force verification with mesh resolution results.

The M1, M2, M3, M4 and M5 are represent mesh resolution models. The verification in this study revealed the followings comparison of plane die force average less than 5 percent error are shown in Table 5. It could be explained the M3 was suitable model in FE.

Table 5 The comparison model and percent error.

\begin{tabular}{|l|r|}
\hline Comparison Model & Percent Error (\%) \\
\hline M1 Vs M2 & 12.527 \\
\hline M2 Vs M3 & 11.274 \\
\hline M3 Vs M4 & 4.807 \\
\hline M4 Vs M5 & 4.721 \\
\hline
\end{tabular}

\section{Results and Discussion}

The change in mechanical properties base on FE simulations can be rationalized from normal stress in relative velocity. It could be observed the punch speed is not significantly values in Static Structural theory because the relative velocity in governing equation was slightly values.

Since the first increment sheet was moving down, the interactions between die areas node to finally state $20 \mathrm{~mm}$ distance. The intensity of normal stress was deepened on the edge of arc curve. Leading to FE simulation can be calculated the wear index with the effect of drawing angle, which could be explained in Fig. 7. The results were 
decrease by increasing sliding node angle along arc length of drawing die surface. This cloud also be explained by the fact that the direction of material flow between node of sheet and die respectively.

The polynomial equation (Order 5 ) can be explained and predicted the characteristics effect of wear index in function of drawing angle by Eq. (7).

$$
y=A\left(\beta^{5}\right)+B\left(\beta^{4}\right)-C\left(\beta^{3}\right)+D\left(\beta^{2}\right)-E(\beta)+F
$$

Table 6 The constants values of Eq. (7)

\begin{tabular}{|c|r|r|}
\hline Constants & Values & Unit \\
\hline$y$ & Wear Index $(\mathrm{WI})$ & $\mathrm{m}$ \\
\hline$\beta$ & Drawing Angle & $\left(-^{\circ}\right)$ \\
\hline$A$ & $1.3\left(10^{-16}\right)$ & $\mathrm{m}$ \\
\hline$B$ & $3.8\left(10^{-14}\right)$ & $\mathrm{m}$ \\
\hline$C$ & $4.4\left(10^{-12}\right)$ & $\mathrm{m}$ \\
\hline$D$ & $2.6\left(10^{-10}\right)$ & $\mathrm{m}$ \\
\hline$E$ & $8.1\left(10^{-9}\right)$ & $\mathrm{m}$ \\
\hline$F$ & $1.3\left(10^{-7}\right)$ & $\mathrm{m}$ \\
\hline
\end{tabular}

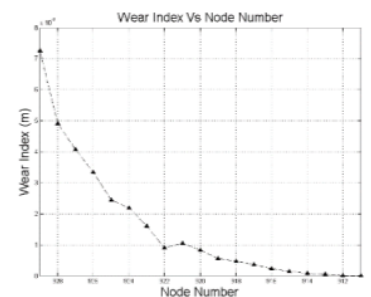

(a)

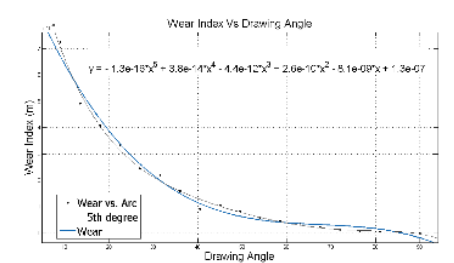

(b)
Fig 7. (a) The Wear Index along the arc length nodes and (b) The polynomial fitting equation of wear index depended on drawing angle.

\section{Conclusions}

This model is the simple method utilized to evaluate the characteristics of tool wear in die geometry. For additional the range of TiN coating thickness was between 1 to $5 \mu \mathrm{m}$, the resolving of galling on die surface was depended on various parameter in stamping process such as sampling per minute (SPM), lubrication, material geometry shape, surface roughness and cleanness etc.

\section{Acknowledgements}

The authors would like to acknowledge the technical support of National Metal and Materials Technology Center (MTEC) and Department of Industrial Engineering, Faculty of Engineering, Nakhon Phanom University. In addition, the authors would like to sincerely thank Dr.Numpon Mahayotsanun (Khon Kaen University) and Mr. Sedthawatt Sucharitpwatskul (MTEC) for their suggestions and advice.

\section{References}

1. Automotive, Railways, Transport, "Next generation vehicle Stainless steel in structural automotive applications," 2009, vol. 2009, no. 10, p. 53.

2. M. Wallmeier, E. Linvill, M. Hauptmann, J.-P. Majschak, and S. Östlund, "Explicit FEM analysis of the deep drawing of paperboard," Mech. Mater., vol. 89, pp. 202-215, Oct. 2015.

3. M. Tropp, M. Tomasikova, R. Bastovansky, L. Krzywonos, and F. Brumercik, "Concept of Deep Drawing Mechatronic System Working in Extreme Conditions," Procedia Eng., vol. 192, pp. 893-898, Jan. 2017.

4. A. K. Choubey, G. Agnihotri, and C. Sasikumar, "Numerical Validation of Experimental Result in Deep-Drawing," Mater. Today Proc., vol. 2, no. 4, pp. 1951-1958, Jan. 2015.

5. R. Dwivedi and G. Agnihotri, "Study of Deep Drawing Process Parameters," Mater. Today Proc., vol. 4, no. 2, Part A, pp. 820-826, Jan. 2017.

6. L. Luo, Z. Jiang, and D. Wei, "Influences of microfriction on surface finish in micro deep drawing of SUS304 cups," Wear, vol. 374-375, pp. 36-45, Mar. 2017.

7. M. Chen et al., "Local Stress Evaluation During Deformation in SUS304 Austenitic Stainless Steel," Mater. Today Proc., vol. 2, pp. S937-S940, Jan. 2015.

8. L. Fernandes, F. J. G. Silva, M. F. Andrade, R. Alexandre, A. P. M. Baptista, and C. Rodrigues, "Improving the punch and die wear behavior in tin coated steel stamping process," Surf. Coat. Technol., vol. 332, pp. 174-189, Dec. 2017.

9. H. Cicek, "Wear behaviors of TiN/TiCN/DLC composite coatings in different environments," Ceram. Int., vol. 44, no. 5, pp. 4853-4858, Apr. 2018.

10. G. Zheng, G. Zhao, X. Cheng, R. Xu, J. Zhao, and H. Zhang, "Frictional and wear performance of TiAlN/TiN coated tool against high-strength steel," Ceram. Int., vol. 44, no. 6, pp. 6878-6885, Apr. 2018.

11. R. K. Blandford, D. K. Morton, S. D. Snow, and T. E. Rahl, "Tensile Stress-Strain Results for 304L and 316L Stainless Steel Plate at Temperature," pp. 617628, Jan. 2007.

12. R. C. Cozza, "A study on friction coefficient and wear coefficient of coated systems submitted to micro-scale abrasion tests," Surf. Coat. Technol., vol. 215, pp. 224-233, Jan. 2013.

13. X. Li, J. Chen, L. Ye, W. Ding, and P. Song, "Influence of strain rate on tensile characteristics of SUS304 metastable austenitic stainless steel," Acta Metall. Sin. Engl. Lett., vol. 26, no. 6, pp. 657-662, Dec. 2013.

14. J. Chang, H. Chenyuan, and J. Xiaoxiong, "FE simulation of tire wear with complicated tread pattern," Procedia Eng., vol. 15, pp. 5015-5019, Jan. 2011.

15. M. E. Gurtin, V. J. Mizel, and W. O. Williams, "A note on Cauchy's stress theorem," J. Math. Anal. Appl., vol. 22, no. 2, pp. 398-401, May 1968. 